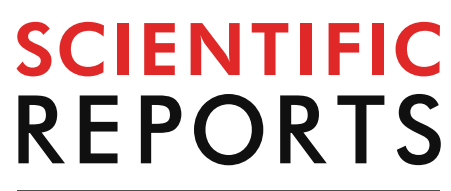

natureresearch

Check for updates

\title{
Demystifying biotrophs: FISHing for mRNAs to decipher plant and algal pathogen-host interaction at the single cell level
}

\author{
Julia Badstöber ${ }^{1}$, Claire M. M. Gachon ${ }^{2,3}$, Jutta Ludwig-Müller ${ }^{4}$, Adolf M. Sandbichler ${ }^{5}$ \&
} Sigrid Neuhauser ${ }^{1 \bowtie}$

Plant-pathogen interactions follow spatial and temporal developmental dynamics where gene expression in pathogen and host undergo crucial changes. Therefore, it is of great interest to detect, quantify and localise where and when key genes are active to understand these processes. Many pathosystems are not accessible for genetic amendments or other spatially-resolved gene expression monitoring methods. Here, we adapt single molecule FISH techniques to demonstrate the presence and activity of mRNAs at the single-cell level using phytomyxids in their plant and algal host in lab and field material. This allowed us to monitor and quantify the expression of genes from the clubroot pathogen Plasmodiophora brassicae, several species of its Brassica hosts, and of several brown algae, including the genome model Ectocarpus siliculosus, infected with the phytomyxid Maullinia ectocarpii. We show that mRNAs are localised along a spatiotemporal gradient, thus providing a proofof-concept of the usefulness of single-molecule FISH to increase knowledge about the interactions between plants, algae and phytomyxids. The methods used are easily applicable to any interaction between microbes and their algal or plant host, and have therefore the potential to rapidly increase our understanding of key, spatially- and temporally-resolved processes underpinning complex plantmicrobe interactions.

Thanks to a series of technological advances over the last years, it has become clear that many biological processes within and between organisms are best studied at the single cell level e.g. ${ }^{1,2}$. Single cell approaches provide a revolutionary toolset to study interactions, especially the complex intermingled crosstalk between biotrophic pathogens and their algal or plant hosts, when they cannot be grown outside of the host and/or are not amenable to genetic modifications. Biotrophs keep their host's cells alive during their development and growth and therefore, have evolved a multitude of strategies to escape detection but to still obtain nutrients or water from their host ${ }^{3,4}$. In such interactions, timing is crucial: the pathogen first needs to escape the host defence while establishing itself, but in a subsequent step the pathogen and host communicate about nutrients to be exchanged. Hence, gene expression changes rapidly at the cellular level, and can differ between neighbouring cells ${ }^{5}$. Unless they are combined with expensive or time-consuming techniques such as laser-assisted microdissection ${ }^{6}$, widely used methods such as qPCR or RNAseq are used. These are not able to account for spatial and temporal heterogeneity between the cells, and therefore are impracticable to study single-cell changes at the scale of organs or macro-organisms. However, transformation or genetic manipulation remains inaccessible for a wide range of pathogens or hosts, especially those that cannot be grown in the laboratory and/or for which only very limited genetic information is available ${ }^{1}$. Furthermore, current work on plant and algal microbiomes makes increasingly clear that functional studies require to take into account complex microbial communities which include a huge diversity of „non-model“ organisms, many of which are not accessible to culturing or genome amendment techniques ${ }^{7-9}$. Also, the specific developmental stages of pathogens within their hosts should be taken

${ }^{1}$ Institute of Microbiology, University of Innsbruck, 6020 Innsbruck, Austria. ${ }^{2}$ The Scottish Association for Marine Science, Scottish Marine Institute, Oban PA37 10A, UK. ${ }^{3}$ UMR 7245 - Molécules de Communication et Adaptation des Micro-organismes, Muséum National d'Histoire Naturelle, CNRS, Paris 75005, France. ${ }^{4}$ Institute of Botany, Technische Universität Dresden, 01217 Dresden, Germany. ${ }^{5}$ Institute of Zoology, University of Innsbruck, 6020 Innsbruck, Austria. ${ }^{\circledR}$ email: Sigrid.Neuhauser@uibk.ac.at 
into account. Thus, descriptive approaches such as Fluorescence In Situ Hybridisation (FISH) have a renewed potential to start exploring these communities functionally.

Indeed, most single-cell approaches available currently lack the potential to be used routinely outside of model organisms to study the dynamic transcriptomic changes of single cells. One notable exception is the in situ localisation of individual mRNAs via FISH ${ }^{1,10,11}$. FISH techniques have been utilised to study gene expression patterns and the distribution of mRNA genes in human cell lines ${ }^{12}$, different animal models e.g. ${ }^{13}$, fungi and yeasts e.g. ${ }^{14}$ and plants ${ }^{15-17}$. Recent improvements involving fluorophores, microscopic detection and resolution now allow to localise individual mRNAs of interest ${ }^{5}$. Patterns of mRNA expression and the subcellular localisation of mRNAs can thus be accessed. Ultimately this leads to a better understanding of the regulatory processes behind the translation of genetic information ${ }^{18}$, without requiring genetic manipulation of the organism of interest, nor the availability of extensive genetic and molecular data. Additionally, this can be applied to field-collected samples, which opens new research lines for uncultivable organisms once an mRNA sequence of interest is available.

Phytomyxea (Rhizaria, Endomyxa) are a group of economically important plant pathogens, including e.g. Plasmodiophora brassicae, the clubroot pathogen, causing a loss of roughly $10 \%$ of the world brassica crop production ${ }^{20}$. Additionally, ten phytomyxid species parasitize important marine primary producers, namely brown algae, seagrasses and diatoms, with essentially unknown ecological consequences ${ }^{21,22}$. In brown algae, the galls formed by Maullinia braseltonii on the Pacific bull kelp (Durvillea antartica) affect the commercial value of this locally important food source. Its closely related parasite, Maullinia ectocarpii, infects a broad range of filamentous algae spanning at least four orders, including the genome model Ectocarpus siliculosus and gametophytes of the giant kelp Macrocystis pyrifera ${ }^{23}$. Its availability in laboratory culture makes it a good model to start deciphering the interaction between phytomyxids and their marine hosts.

Despite their importance as plant and algal pathogens, Phytomyxea have been difficult to study, mostly because they cannot be cultured without their host and because they have a complex multi-stage life cycle ${ }^{20}$. This life cycle comprises two functionally different types of heterokont zoospores (primary and secondary), multinucleate plasmodia (sporangial and sporogenic), zoosporangia and resting spores. Primary zoospores (Fig. 1e) infect suitable hosts (Fig. 1f) and develop into multinucleate sporangial plasmodia (Fig. 1a) which mature (Fig. 1b,c) and release primary or secondary zoospores (Fig. 1d). This sporangial part of the life cycle is often restricted to few host cells. Secondary zoospores develop into multinucleate sporogenic plasmodia (Fig. 1g) which can grow to considerable size inside of the host, which in some species results in the typical hypertrophies. The sporogenic part of the life cycle ends in the formation of the resistant resting spores (Fig. 1h). Resting spores are passively released from the disintegrating host tissue and can persist for decades in the environment.

Genome and transcriptome data became available only recently for P. brassicae ${ }^{24,25}$. Yet the unavailability of genetic manipulation of the parasite forces all functional studies to be conducted on transformed plant hosts (mainly A. thaliana) either focussing on the host side of the response e.g. ${ }^{26}$ or by overexpressing P. brassicae genes in the host ${ }^{27}$ or in other plant pathogenic fungi ${ }^{28}$. Likewise, genome resources are available for brown algae ${ }^{29,30}$, but this group yet remains inaccessible to transformation, genome editing or RNAi, to the exception of Fucus zygotes $^{31}$. Apart from taxonomic markers, no molecular information is currently available for M. ectocarpii or any other marine phytomyxid nor can it be genetically modified. In this context, the prospect of monitoring gene expression of phytomyxean parasites in their host, linking the expression of selected genes of interest to specific stages of the life cycle and to specific time points in the development of the pathogen, is to get a better understanding of the interaction and the possible function of such a particular gene.

Here, we developed tools to monitor gene expression of intracellular pathogens and to monitor the response of their hosts (plants and brown algae) upon infection. We provide a proof-of-concept of the usefulness of singlemolecule FISH to increase knowledge about the complex interactions between plants, algae and phytomyxids. For this purpose, two different approaches of mRNA localisation were evaluated: single molecule FISH (smFISH), which is based on a series of fluorescently labelled probes that tile along the mRNA of interest ${ }^{15}$ and Rolling Circle Amplification-FISH (RCA-FISH), which is based on in situ transcription of RNA followed by in situ-RCA signal amplification $^{12}$. Genes were selected on the basis of available biological background, to allow to not only test and validate FISH methods, but to also validate the feasibility and usefulness of these methods to disentangle biological information. The following P. brassicae genes were selected (1) the housekeeping gene Actin1 (GenBank: AY452179.1) $)^{32}$ (2) a SABATH-type methyltransferase from P. brassicae (PbBSMT, GenBank: JN106050.1 $1^{33}$, which is able to methylate the plant defence compound salicylic acid (SA), as well as benzoic and anthranilic acids. To monitor mRNA expression and localisation in the host, the following genes were tested: (1) the Brassica rapa maltose excess protein 1 (MEX1, GenBank: XM_009109278.2) that encodes a maltose transporter, and (2) the vanadium-dependent bromoperoxidase ( $v B P O)$ of E. siliculosus Ec32m (Genbank: CBN73942.1), encoding a stress-inducible enzyme assumed to halogenate defensive host secondary metabolites ${ }^{34,35}$.

\section{Methods}

Preparation and storage of the biological material. Clubroot-infected Brassica plants. Field sampling. Clubroot infected white cabbage (Brassica oleracea var. capitata f. alba), broccoli (Brassica oleracea var. italica), Chinese cabbage (Brassica rapa ssp. pekinensis) and kohlrabi (Brassica olearacea var. gongylodes) were collected from a commercial field (Ranggen, Austria, $47^{\circ} 15^{\prime} 24^{\prime \prime} \mathrm{N}, 11^{\circ} 13^{\prime} 01^{\prime \prime} \mathrm{E}$ ). Clubroots were rinsed with tap water and treated as described below.

Inoculation and cultivation of plants. Chinese cabbage (Brassica rapa cv. 'Granaat', European Clubroot Differential Set ECD-05) seeds were germinated on wet tissue paper for three days and then planted in a potting soil mixture ( $\mathrm{pH} \sim 5.7$, mixing standard compost, rhododendron soil and sand 4:2:2). Plants were grown with 

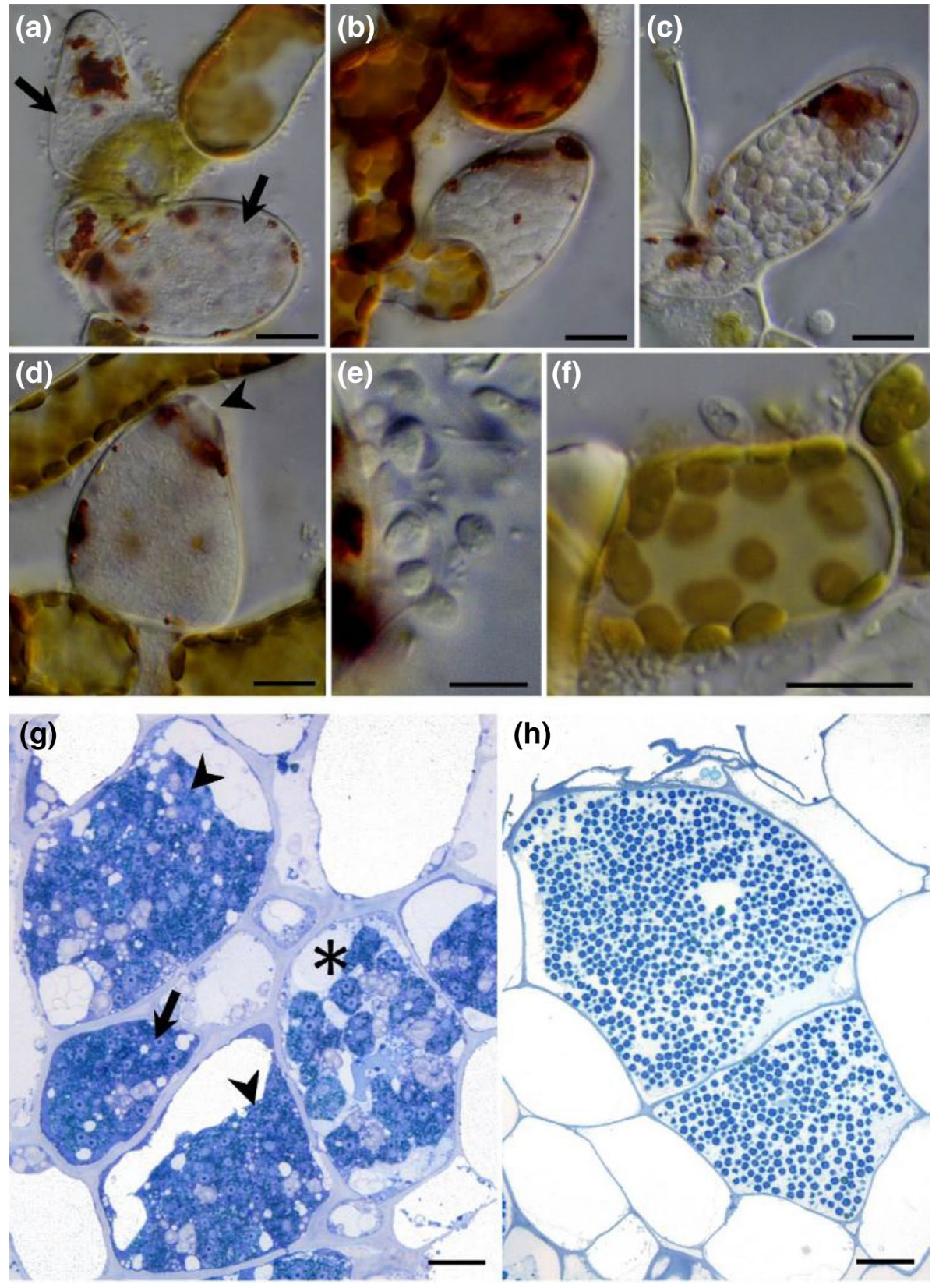

(h)
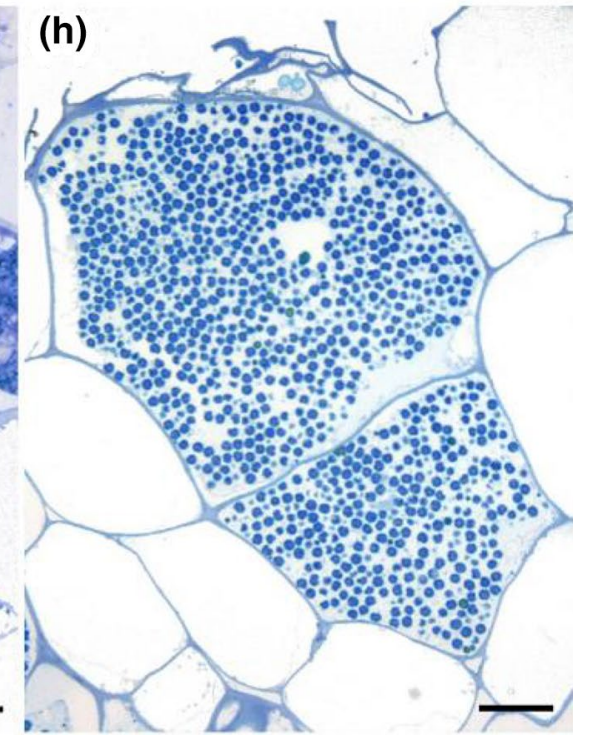

Figure 1. Phytomyxid morphology. Sporangial life cycle of Maullinia ectocarpi $i^{19}$ and sporogenic development of $P$. brassicae (g,h). (a-f) Maullinia ectocarpii infecting filaments of the brown algae Macrocystis pyrifera. Pale cells are filled with the parasite. (a) sporangial plasmodia in enlarged algal cells (arrows). (b) sporangial plasmodium transitioning to form a zoosporangium. (c) Mature zoosporangium filled with zoospores. (d) Empty sporangium after the primary zoospores were released through an apical opening (arrowhead). (e) Primary zoospores with two anterior flagella. (f) Primary zoospore infecting the algal filament. (g,h) Chinese cabbage clubroots, cross section, methylenblue staining (g) multinucleate, sporangial plasmodia in different developmental stages. Actively growing, sporogenic plasmodia (arrow, arrowheads) and one plasmodium showing the typical lobose structure (asterisk). (h) P. brassicae resting spores. All resting spores inside of one host cell were formed from the same sporogenic plasmodium. Bars $=10 \mu \mathrm{m}$.

a photoperiod of $12 \mathrm{~h}$. After 12 days, plants were inoculated with $7 \times 10^{6}$ spores of $P$. brassicae. Root galls were harvested after six to seven weeks.

Sample fixation and preparation. Clubroots were cut into ca. $3 \times 4 \mathrm{~mm}$ pieces to allow for a more homogenous fixation. Samples were transferred into Histofix 4\% (phosphate-buffered formaldehyde solution, Carl Roth) where they remained for 1-12 h depending on sample size. Samples were used directly, or were washed in 


\begin{tabular}{|c|c|}
\hline Oligonucleotide & Sequence \\
\hline \multicolumn{2}{|c|}{ PbBSMT (GenBank: JN106050.1) } \\
\hline LNA primer $P b B S M T$ & 5' CCC GTT CAC CTG GCA TGA CTA TTC G 3' \\
\hline Padlock probe $P b B S M T$ & 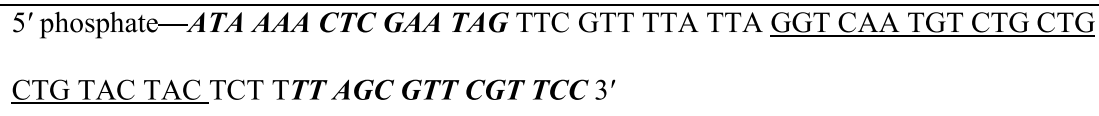 \\
\hline Detection probe $P b B S M T$ & 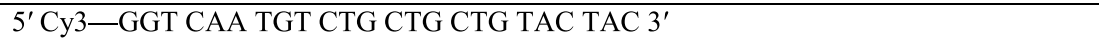 \\
\hline \multicolumn{2}{|c|}{ Actin1 (GenBank: AY452179.1) } \\
\hline LNA primer Actin 1 & 5' CGT ACC AGT CGA TCA TGA AGT GCG ACG 3' \\
\hline Padlock probe Actin 1 & 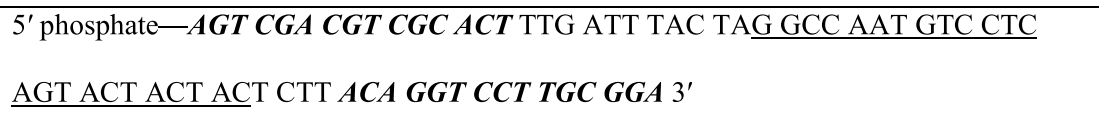 \\
\hline Detection probe Actin 1 & $5^{\prime}$ Cy3-GGC CAA TGT CCT CAG TAC TAC TAC 3' \\
\hline
\end{tabular}

Table 1. RCA-FISH probes. PbBSMT (GenBank: JN106050.1) and Actin1 (GenBank: AY452179.1) are genes of $P$. brassicae. LNA modified nucleotides are shown in orange, padlock probe target-specific parts are shown in italics and bold letters and the detection sequences are shown underlined.

an ascending ethanol series for long-term storage (50\%, 80\%, $2 \times 96 \%$; all dilutions made with DEPC [diethyl pyrocarbonate]-treated water) and stored at $-20^{\circ} \mathrm{C}$ until use.

Clubroots (or clubroot pieces) were cut transversal with an RNase free razor blade by hand and washed with $1 \times$ PBS buffer (phosphate-buffered saline, $137 \mathrm{mM} \mathrm{NaCl}, 10 \mathrm{mM}$ phosphate, $2.7 \mathrm{mM} \mathrm{KCl}$, DEPC treated water). Making the cuts by hand posed a significantly lower risk of RNase contamination than using a cryotome (Reichert-Jung, Frigocut 2800, Suppl. Note S1).

Growth and maintenance of M. ectocarpii infected Ectocarpus siliculosus Ec32m and Macrocystis pyrifera. Ectocarpus siliculosus (fully sequenced genome strain Ec32m, CCAP 1310/4) was infected with M. ectocarpii (CCAP 1538/1), using a clonal culture of $M$. pyrifera female gametophyte (CCAP 1323/1) as an intermediate host, as described by ${ }^{35}$. Cultures were maintained at $15^{\circ} \mathrm{C}$ with $12 \mathrm{~h}$ photoperiod, 20 micromol photon $\mathrm{m}^{-2} \mathrm{~s}^{-1}$ in artificial seawater (ASW) with half strength modified Provasoli ${ }^{36}$. Cultures were regularly checked microscopically and samples were harvested and fixed as described above, replacing DEPC-treated water by DEPC-treated ASW. Samples were stored at $-20^{\circ} \mathrm{C}$ until use.

mRNA visualisation. To prevent RNase contamination, experiments were done in RNase-free environment with RNase-free reaction mixtures. To avoid photobleaching, the samples were protected from light during and after the hybridisation of the fluorescently labelled oligonucleotides. All enzymes and reaction mixtures were kept on ice during use. Reaction tubes were incubated using a PCR cycler with heated lid to avoid evaporation or a thermal block. All incubation and amplification steps were performed in $0.2 \mathrm{ml}$ PCR reaction tubes unless otherwise stated.

Two P. brassicae genes were analysed using RCA-FISH: the SABATH-type methyltransferase PbBSMT and Actin1. In contrast to Actin1, a spatiotemporal expression pattern has already been hypothesised for PbBSMT since only low expression of the transcript was detected during early time points of infection and it only later increased $^{33}$; thus we also analysed its expression using smFISH to compare the performance of both methods, qualitatively and quantitatively.

RCA-FISH (rolling circle amplification-Fluorescence in Situ Hybridisation). RCA-FISH is based on the in situ reverse-transcription of mRNA, a subsequent signal amplification using a loop-shaped DNA target probe as starting point for the RCA amplification and followed by FISH detection of the so amplified DNA (Table 1$)^{12}$. Experimentally this process can be divided into four steps: (1) Reverse transcription of target mRNAs, using a mRNA specific locked nucleic acid (LNA) primer. (2) RNase H digestion of the RNA part of the RNA/DNA hybrid sequence, because in all subsequent steps the cDNA generated by the reverse transcription serves as template. (3) RCA amplification: A so-called padlock probe, which forms a little loop when binding to the cDNA, serves as circular DNA template for RCA. The loop like sequence is amplified and as a part of it a sequence complementary to the detection probe. (4) Signal detection: A standard FISH probe is used to detect the amplified signal. 
Primer and probe design. LNA-primer. LNA primers were approximately 25 bp long and located close to the $3^{\prime}$ end of the mRNA. Starting from the $5^{\prime}$ end of the LNA primer, every second nucleotide was replaced by its LNA counterpart, in total 7 LNAs (Table 1).

Padlock probe. About $15 \mathrm{bp}$ at each of the $3^{\prime}$ and $5^{\prime}$ ends of the padlock probe are complementary to the cDNA sequence. When these two regions bind to the cDNA, the central region of the probe (ca. $50 \mathrm{bp}$ ) forms a loop, similar to the shackle of a padlock. This central region contains a generic detection sequence ( $\sim 23 \mathrm{bp})$ flanked by random filler sequences (Table 1). This loop-like structure serves as target for the Phi-Polymerase mediated RCA which is amplifying the detection sequence and consequently the signal. The padlock probe has to be phosphorylated before use. Overall the structure of the padlock probe is: 5 ' phosphate-15 bp complementary to cDNA - 5-15 bp random filler-detection sequence-5-15 bp random filler-15 bp complementary to cDNA-3'.

Detection probe. This is a fluorescent, mono-labelled FISH probe complementary to the detection sequence included in the padlock probe.

To check the secondary structures in all three types of probes, UNAFold (https://eu.idtdna.com/UNAFold) was used. Specificity and potential off-target binding sites were checked by blasting the sequences (https://blast .ncbi.nlm.nih.gov/) against the nr database. RCA FISH probes were ordered via www.eurogentec.com.

RCA-FISH experimental method. A tick-off style, step-by-step protocol is provided in Suppl. Note S2. Modifications and notes on filamentous starting material is provided in Suppl. Note S1.

Sections from clubroot samples or algal material were transferred into the reaction tubes were they were rehydrated in PBS-T (0.05\% Tween-20 in $1 \times$ PBS). Several sections may be treated in one tube, as long as the material is submerged in the reaction mix. For our samples $50 \mu \mathrm{l}$ of reaction mix were required for consistent

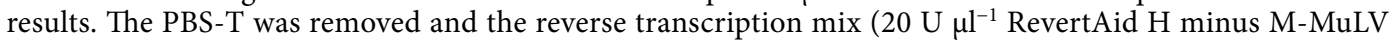

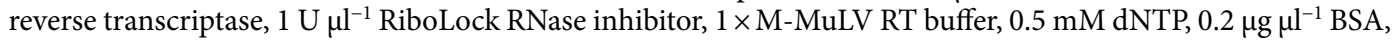
$1 \mu \mathrm{M}$ LNA primer) was added. Samples were incubated for $1 \mathrm{~h}$ at $37^{\circ} \mathrm{C}$ in a PCR cycler. Samples were washed twice with PBS-T and were then incubated in 3.7\% PFA (paraformaldehyde in $1 \times$ PBS) for 5 min at room temperature. Samples were washed in PBS-T. This was followed by RNase H digestion, hybridisation and ligation of the padlock probe in the hybridisation mix ( $1 \mathrm{U}_{\mu} \mathrm{l}^{-1}$ Ampligase, $0.4 \mathrm{U} \mu \mathrm{l}^{-1} \mathrm{RNase} \mathrm{H}, 1 \mathrm{U} \mu \mathrm{l}^{-1}$ RiboLock RNase inhibitor, $1 \times$ Ampligase buffer, $0.2 \mu \mathrm{g} \mu \mathrm{l}^{-1} \mathrm{BSA}, 0.05 \mathrm{M} \mathrm{KCl}, 20 \%$ formamide, $0.1 \mu \mathrm{M}$ padlock probe). Samples were incubated for $15 \mathrm{~min}$ at $45^{\circ} \mathrm{C}$ and washed in PBS-T. Rolling circle amplification was done for $45 \mathrm{~min}$ at $37^{\circ} \mathrm{C}$ (polymerase reaction mix: $1 \mathrm{U} \mathrm{\mu l}^{-1}$ Phi29 DNA polymerase, $1 \mathrm{U} \mathrm{\mu l}^{-1}$ RiboLock RNase inhibitor, $1 \times$ Phi29 buffer, $0.25 \mathrm{mM}$ dNTP, $0.2 \mu \mathrm{g} \mu \mathrm{l}^{-1} \mathrm{BSA}, 5 \%$ Glycerol), followed by a PBS-T washing step. The detection probe was hybridised for $10 \mathrm{~min}$ at $37^{\circ} \mathrm{C}$ in a detection probe reaction mix $(1 \times$ hybridisation mix $(2 \times$ SSC saline-sodium citrate buffer ( $300 \mathrm{mM}$ sodium chloride, $30 \mathrm{mM}$ sodium citrate), $40 \%$ (vol/vol) formamide, $0.1 \mu \mathrm{M}$ detection oligonucleotide). Samples were washed twice with PBS-T. Samples were carefully transferred and arranged on microscope glass slides, mounted with Vectashield (H-1000, Vector Laboratories) mounting medium and covered with a coverslip. The coverslips were sealed with clear nail polish and the slides were imaged using a laser scanning microscope (see "image acquisition and data analyses" for details). To exclude the possibility of false positive signals, control samples were treated without padlock probes.

Single molecule FISH (smFISH). smFISH relies on a large number of mono-labelled DNA-probes complementary to the mRNA sequences of interest. The protocol described here was adapted from ${ }^{15}$. Probes for $\mathrm{smFISH}$ were designed and ordered using the Stellaris Probe Designer (https://singlemoleculefish.com, all probes labelled with Quasar570) or ordered via https://biomers.net/ (Cy3 labelled probes). A set of 48 different probes was generated, complementary to our mRNA sequences of interest (PbBSMT GenBank: JN106050.1, vBPO GenBank CBN73942.1, MEX1 GenBank: XM_009109278.2, Suppl. Tab. S1-3). To verify the specificity of the oligonucleotides to the target sequence, the sequences were blasted against the NCBI nr database.

smFISH experimental method. A tick-off style step-by-step protocol is provided in Suppl. Note S3.

Samples were washed in $1 \times$ PBS buffer and were transferred to $0.2 \mathrm{ml}$ PCR tubes and incubated for $1 \mathrm{~h}$ in $70 \%$ $\mathrm{EtOH}$ at room temperature. The $\mathrm{EtOH}$ was removed and samples were washed twice for three minutes in washing buffer ( $10 \%$ formamide, $2 \times \mathrm{SSC})$. Samples were then incubated in $50 \mu \mathrm{l}$ of hybridisation buffer $\left(100 \mathrm{mg} \mathrm{ml}^{-1}\right.$ dextran sulfate, $40 \%$ formamide in $2 \times$ SSC, $250 \mathrm{nM}$ probe-mix) in a PCR cycler at $37^{\circ} \mathrm{C}$ overnight with the lid heated to $100{ }^{\circ} \mathrm{C}$ to prevent evaporation. Subsequently, the hybridisation buffer was removed and the samples were rinsed twice with washing buffer, before being incubated in the washing buffer at $37^{\circ} \mathrm{C}$ for $30 \mathrm{~min}$. Nuclei were counterstained in $50 \mu \mathrm{l}$ 4,6-diamidino-2-phenylindole (DAPI) solution (100 $\mathrm{ng}^{-1}$ in washing buffer) for $15 \mathrm{~min}$ at $37^{\circ} \mathrm{C}$. Samples were washed in $50 \mu \mathrm{l} 2 \times \mathrm{SSC}$ for $1 \mathrm{~min}$ before being equilibrated in $50 \mu \mathrm{GLOX}$ buffer $(0.4 \%$ glucose in $10 \mathrm{nM}$ Tris-HCl, $2 \times \mathrm{SSC})$ for $3 \mathrm{~min}$, followed by $50 \mu \mathrm{l}$ GLOX buffer containing enzymes $(1 \%$ glucose oxidase and $1 \%$ catalase in GLOX buffer) after removal. Samples were carefully mounted using tweezers in the GLOX buffer containing enzymes. The mounted samples were sealed with nail polish and imaged as soon as possible to avoid a reduction of image quality.

To confirm RNA specificity and to evaluate autofluorescence of the samples, control samples were treated with RNase or were analysed without the addition of smFISH probes. RNase A treatment for sample sections was performed for $1 \mathrm{~h}$ at $37^{\circ} \mathrm{C}\left(100 \mu \mathrm{g} \mathrm{ml}^{-1}\right)$ before the hybridisation step (Supplementary Note S3, between steps 4 and 5). After RNase A digestions the samples were washed twice in $10 \mathrm{mM} \mathrm{HCl}$ for $5 \mathrm{~min}$ and rinsed twice in $2 \times$ SSC for $5 \mathrm{~min}$. These samples were then incubated with the smFISH probes as described above. Quasar570 
labelled smFISH probes where used with the corresponding Stellaris buffers. Those samples were mounted in Roti-Mount FluorCare (Carl Roth).

All experiments were performed using multiple biological and technical replicates. For each experiment 2-3 infected individuals were selected as biological replicates. From each of this biological replicate at least 5 sample sections were generated as technical replicates. So a total of 10-15 sections were analyzed microscopically. These experiments were repeated at least 5 times at different dates using different infected individuals (or controls).

Image acquisition and data analyses. RCA FISH and smFISH images were acquired with a Leica SP5II confocal laser scanning microscope (CLSM), using the LAS AF software (version 2.7, Leica Microsystems, Germany) and a Zeiss Cell Observer.Z1 Spinning Disk microscope using the ZEN software (Carl Zeiss Microscopy, Germany). The Leica SP5-II CLSM was equipped with a hybrid detector and a $20 \times(0.7$ NA) or $63 \times(1.3$ NA) objective lens and with the following lasers: $405 \mathrm{~nm}, 458 \mathrm{~nm}, 514 \mathrm{~nm}, 561 \mathrm{~nm}, 633 \mathrm{~nm}$. For probes labelled with Cy3 (Actin1, PbBSMT, and vBPO) and Qu570 (MEX1), an excitation of $514 \mathrm{~nm}$ was used and the emission was detected at 550-585 nm. For DAPI staining, $405 \mathrm{~nm}$ excitation was used and emission was detected at 430-485 nm. The Zeiss Axio Cell Observer.Z1 was equipped with a CSU-X1 spinning disc confocal using $25 \times$, $40 \times$ or $63 \times$ water-immersion lenses. Raw image stacks were deconvoluted with the Huygens software package (Scientific Volume Imaging, The Netherlands). Images were analysed using ImageJ (https://imagej.net) ${ }^{37}$ which was used to generate coloured overlay images of the different emissions recorded and for creating maximum projections of the z-stacks. Resizing and linear brightness and contrast adjustments were performed in GIMP 2.8.22 (www.gimp.org).

FISH signals in individual stack slices appeared dotted and therefore we used the "find maxima" process in ImageJ to segment and count these dots. With the help of the "find stack maxima" macro this process was automated for every slice in a CLSM stack (Suppl. Fig. S3, S4). CLSM settings were defined in advance to record individual signals in 2 consecutive slices to yield full signal coverage (minimum pinhole settings resulting in a slice thickness of $0.85 \mu \mathrm{m}$; $\mathrm{z}$-stepsize around $0.8 \mu \mathrm{M}$ or below). Noise tolerance values were evaluated preliminary to best fit the fluorescence signal. Regions of interest (ROI) were marked manually (Suppl. Fig. S1, S2, S3), measured and saved. Finally, automated counts of every slice in a stack within a ROI were summarised and normalised to volume and corrected for slice number and $\mathrm{z}$-stepsize. Results are presented in number of FISH signal maxima per $\mu \mathrm{m}^{3}$.

\section{Results}

Qualitative and quantitative comparison of smFISH and RCA-FISH. Localisation of $P b B S M T$ mRNAs resulted in the same spatio-temporal pattern of dotted signals, when smFISH or RCA-FISH were used (Fig. 2a,b, see details in Suppl. Figs. S1, S2, S3, S4, S6-S8). In z-stack maximum projections mRNA signals can appear clustered. However, single signals in individual planes appear as dots with sizes ranging from 0.2 to $0.7 \mu \mathrm{m}$ (Suppl. Fig. S3, S4, Video S1). No signal could be detected in the controls without padlock probe (RCA FISH, Suppl. Fig S5a), after RNase treatment (smFISH, Suppl. Fig. S5b) and in uninfected plant roots (data not shown).

The hypothesised spatiotemporal expression pattern of PbBSMT was identified with RCA-FISH (Fig. 3 g,h,j) and smFISH (Fig. 3i, Suppl. Fig. S8). Specifically, PbBSMT mRNAs started to appear in large quantities once sporogenic plasmodia started to develop into spores (Fig. 3g); the signals appeared dot-like in the individual planes, while in the maximum projection the mRNAs appeared accumulated around the developing spores. With progressing spore formation, the intensity and number of signals intensified around the outside the developing spores, both in individual layers, where most of the signals were still visible as separated dots, and in the maximum projection where mRNA signals appeared to cover the surface of the developing spores (Fig. 3h, see 3D reconstruction in Suppl. Video S1). Subsequently, the signals became fewer and smaller until they disappeared once the spores were fully developed (Fig. 3i). This pattern indicates that the presence of PbBSMT or its mRNA plays a role during the transition from plasmodial growth to sporogenesis in P. brassicae.

In addition to the previously reported increase of $P b B S M T$ expression during the later phases of the pathogen life cycle PbBSMT mRNAs could be detected in plasmodia that clearly were in the very early stage of secondary infection (Suppl. Fig. S5). Those plasmodia were very small in size (ca. $20 \mu \mathrm{m}$ ) and the host cells did not yet show the typical hypertrophied phenotype. This phenotype is typical for cells, which house the much larger, actively growing multinucleate plasmodia that can easily reach $100-150 \mu \mathrm{m}$ in size. The young plasmodia in which the PbBSMT mRNAs were detected did also appear to move from one cell to the next (Suppl. Fig. S6, S7).

The number of signal maxima per $\mu \mathrm{m}^{3}$ was higher with RCA FISH (median $4.47 \times 10^{-02} \pm \mathrm{RSD} 3.01 \times 10^{-02}$ signal maxima $\mu \mathrm{m}^{-3}, \mathrm{n}=9$ ) than with smFISH (median $9.38 \times 10^{-03} \pm \mathrm{RSD} 5.26 \times 10^{-02}$ signal maxima $\mu \mathrm{m}^{3}, \mathrm{n}=37$ Suppl. Tab. 44). However, when smFISH was used, the number of cells in which signals could be detected was considerably higher and more consistent across different samples. Additionally, the detection efficacy of smFISH was higher: more cells produced usable results comparing the number of positive cells per image per experiment (Suppl. Fig. S1, S2). Overall the detection efficacy of RCA FISH was lower (ca. $30 \%$ positive experiments, $\mathrm{n}=16$ ) compared to smFISH (ca. $45 \%$ positive experiments, $\mathrm{n}=35$ ). Therefore, we concluded that for detecting mRNAs in $P$. brassicae smFISH is more suitable: the reduced number of signal maxima $\mu \mathrm{m}^{-3}$ are compensated by a $5-10$ fold increased number of cells with positive signals and a 15\% higher success rate. For this reason, transcripts of Brassica oleracea (MEX1) and E. siliculosus ( $v B P O)$ were analysed with smFISH only.

Microscopic analyses. We also compared CLSM and spinning-disk microscopy. Both methods performed very similar producing complementary mRNA detection patterns (Suppl. Fig. S7). Hand-cutting of clubroot tissue was the best and most reliable method to prepare samples for microscopy (Suppl. Note S1), which resulted 

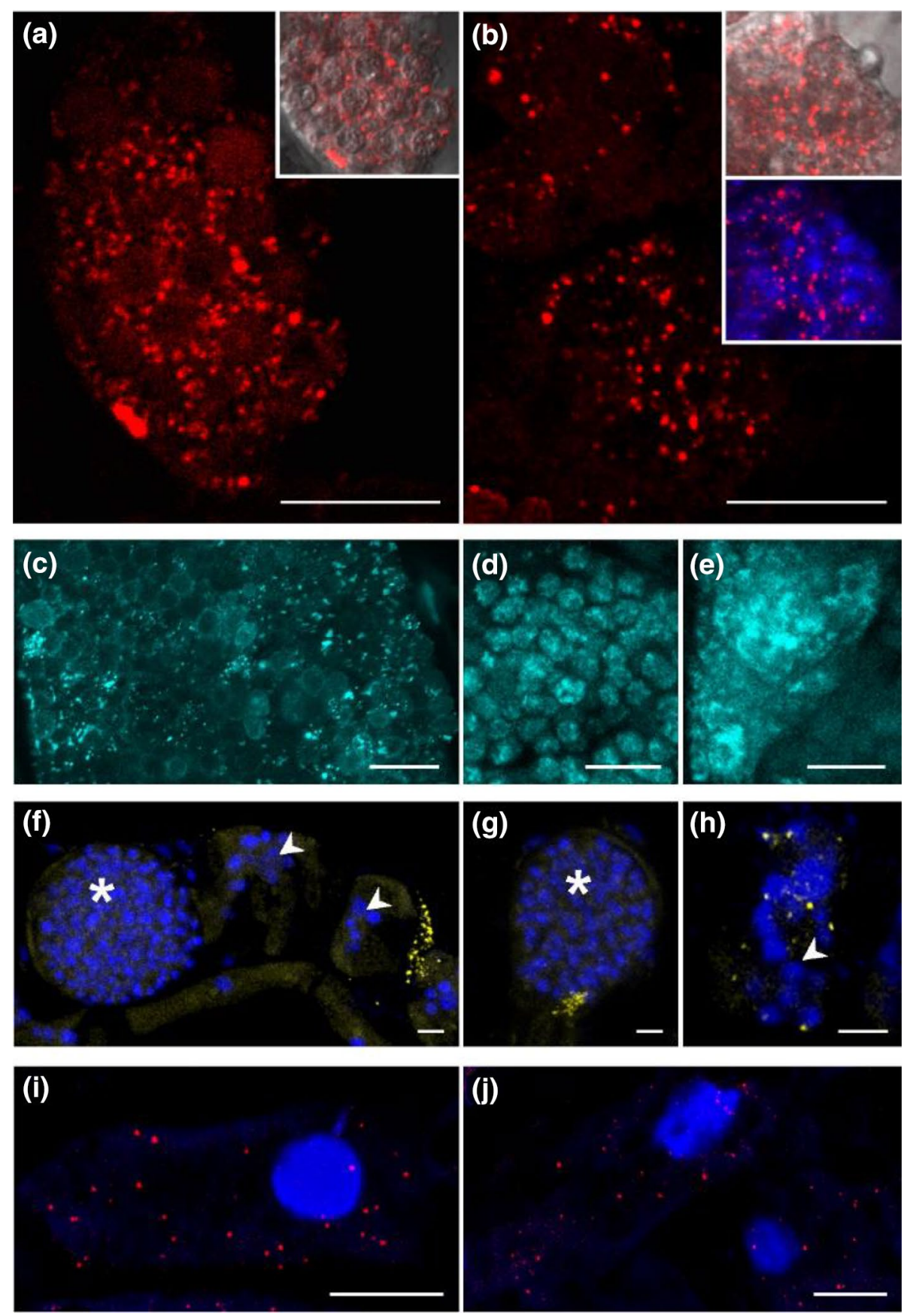

Figure 2. mRNA-transcript localisation in P. brassicae (a-e, Cy3), Ectocarpus siliculosus Ec32m (f-h, Cy3) and Brassica rapa (i,j, Qu570). (a) mRNAs of P. brassicae PbBSMT (red signals), RCA FISH and, (b) smFISH. The plasmodia in (a) and (b) are transitioning from the active growth phase of the plasmodium to resting spore formation, which can be recognised by the round "compartments" visible in the bright field inserts. Multiple nuclei can be seen (b, insert, blue DAPI DNA staining). (c-e) Actin1 mRNAs of P. brassicae using RCA FISH (cyan signals). (c) During the onset of resting spore formation. (d) In the developing resting spores. (e) In actively growing sporogenic plasmodia. (f-h) Localisation of Ec $32 \mathrm{~m} v B P O$ mRNAs (yellow signal) using smFISH, combined with DAPI DNA staining (blue). (f) $v B P O \mathrm{mRNAs}$ close to sporangia of M. ectocarpii. (g,h) $\checkmark B P O$ mRNAs inside of $M$. ectocarpii infected cells. arrowheads: early infection, plasmodia containing several nuclei; asterisks: later infection stage, large plasmodia with numerous parasite nuclei. (i,j): MEX1 mRNAs in the cytosol of infected B. rapa root cells using smFISH (red signals, Quasar 570), combined with DAPI DNA staining (blue). Bright blue structures is accumulated DNA in the plant host nuclei, darker blue structures is DNA in pathogen plasmodia. MEX1 mRNAs are detected near the amyloplasts (black areas). Bars $=10 \mu \mathrm{m}$. Images of the controls of these experiments are provided in Suppl. Fig. S4. 

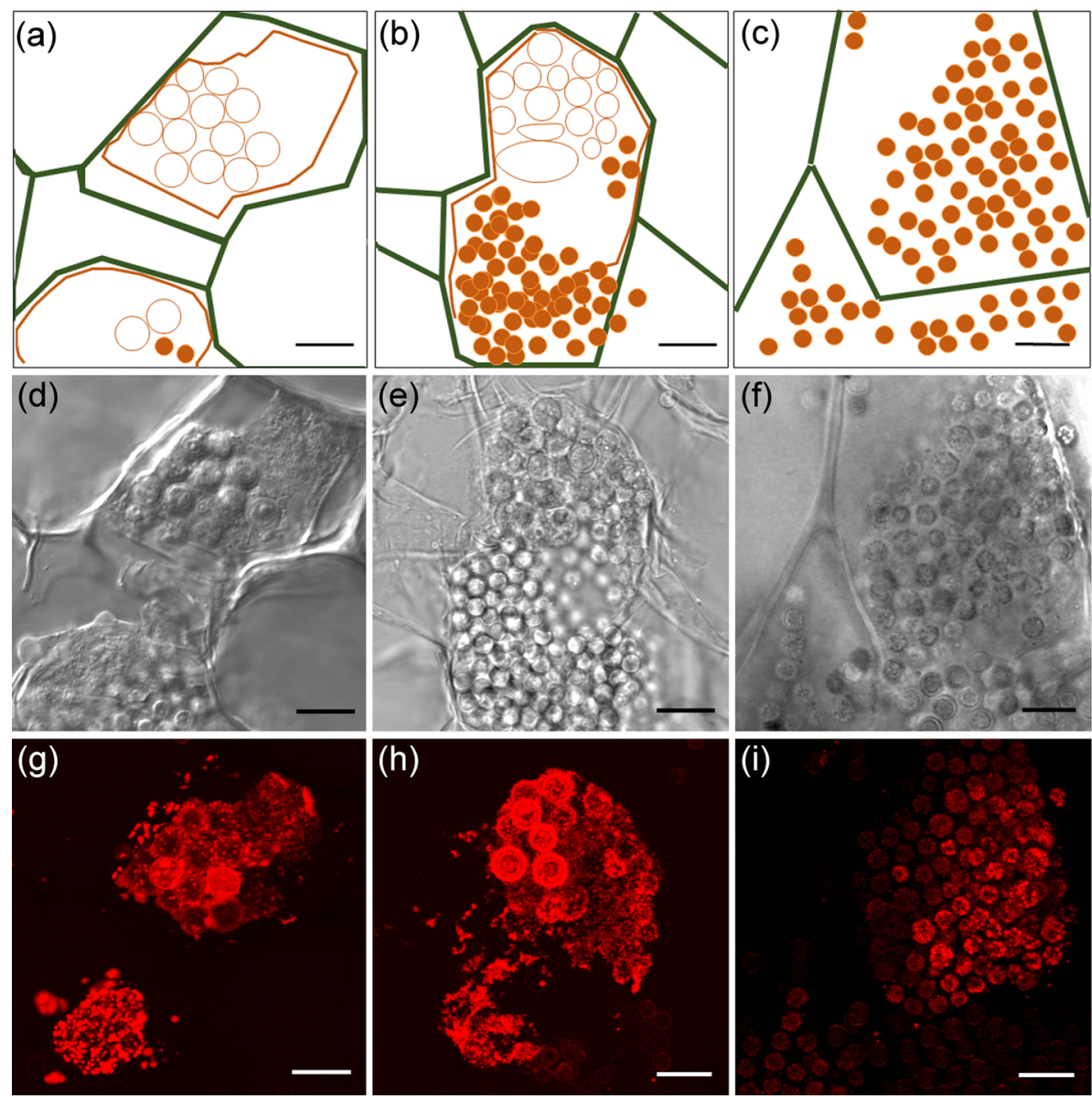

(j)

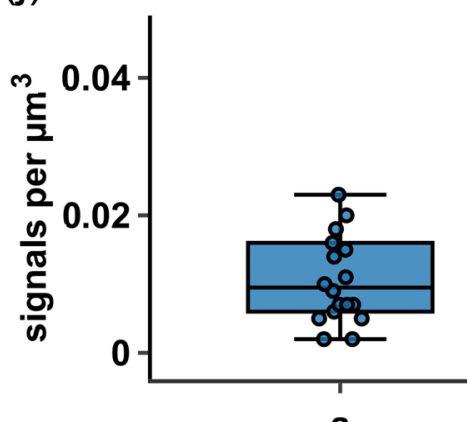

a

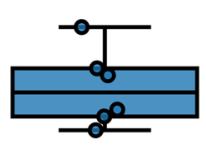

Figure 3. Localisation and quantification of $P b B S M T$ mRNA in $P$. brassicae. (a-c) Diagrammatic overview of the $P$. brassicae structures, $(\mathbf{d}-\mathbf{f})$ the $P$. brassicae structures seen in the brightfield images, $(\mathbf{g}-\mathbf{i})$ and in the FISH images. (j) Signal maxima per cell. (a) The cell that is fully pictured in (a) shows a plasmodium which is at the onset of spore formation (orange polygon) inside a hypertrophied host cell (cell walls are indicated by the green lines). At the onset of spore formation round, spore like aggregations of the plasmodium become visible (orange circles). During this development stage high numbers of mRNAs can be detected (see image $\mathbf{g}$ ) which are randomly distributed when no structures are visible in the plasmodium, but appear aggregated around the spore like structures. When the differentiation of the plasmodium progresses (b) these spore like, aggregated areas become more distinct until they have developed into individual resting spores which are not connected via the plasmodium anymore (orange dots). Signals peak around areas which already start to be recognisable as individual portions and get less in areas where resting spores are formed. Finally, the whole plasmodium has developed into resting spores (c, orange dots), that fill the entire host cell. The mRNA signals decrease further in number and brightness before disappearing completely. Bars $=10 \mu \mathrm{m}$. (j) Signal maxima $\mu \mathrm{m}-3$ of smFISH PbBSMT signals $(\mathrm{n}=37)$ highlighting a peaking of PbBSMT mRNAs during spore formation. Labelling on the $\mathrm{x}$-axes corresponds to the life cycle stages in images $(\mathbf{a}-\mathbf{c})$. No significant correlation was identified. One extreme outliner at 0.088 signals $\mu \mathrm{m}-3$ is not displayed to improve figure layout. 
in slightly uneven samples. Because of this, CLSM was the method of choice because it better allows to analyse thicker samples than wide field and spinning disk microscopy.

Localisation of $\boldsymbol{P}$. brassicae Actin1 by RCA-FISH. The Actin1 mRNA was detected in all life cycle stages of $P$. brassicae (Fig. 2c-e, Suppl. Fig S9), as bright, dot-like structures. Signals were spread evenly within cells (Fig. 2c-e) and could be visualised in individual planes (Suppl. Fig. S9c,d), while in the maximum projection of all optical slices these dots often accumulated to larger signal hotspots (Fig. 2c, Suppl. Fig. S9e,f). In maximum projections dots were sometimes well separated (Fig. 2c), while in other cells the signal was less defined appearing "blurred" and filling most of the cell without clear structural pattern (Fig. 2e), indicating areas with multiple mRNA copies. The controls did not show any comparable signals, only a very weak background of autofluorescence was detected (Suppl. Fig. S5c-e, Fig. S9a,b).

Localisation of host (plant and algal) transcripts during infection by phytomyxids. To evaluate whether it is possible to detect host transcripts within the same samples that host the phytomyxids, two mRNAs were chosen and analysed.

Brassica rapa maltose excess protein 1 (MEX1, smFISH). MEX1 encodes a transporter located in the chloroplast envelope; it is essential for the transport of maltose, the main product of starch breakdown, from the amyloplast to the cytosol ${ }^{38}$. Starch is an important source for sugar within infected tissues to provide nutrients to $P$. brassicae as shown by the accumulation of starch grains in highly infected cells ${ }^{39}$. MEX1 transcripts were detected as clear dots in the cytosol of the Brassica root cells. Dot-like signals could be observed in root cells containing amyloplasts, which were infected with P. brassicae (Fig. $2 \mathrm{i}, \mathrm{j}$ ). The signal for MEX1 was not present in cells filled with spores and cells that did not contain amyloplasts (Suppl. Fig. S10). Similar to the previously described genes localised detection ("dots") could be seen in the individual optical slices and the maximum projection images indicating that mRNAs for MEX1 are present in the whole cytosol of the plant. In both controls, the RNase treated samples and the unlabelled infected samples, no characteristic signals were detected (Suppl. Fig. S5i,j).

Ectocarpus siliculosus vanadium-dependent bromoperoxidase ( $v B P O$, smFISH). mRNA detection in brown algae required adaptations of the protocol. The filamentous growth of E. siliculosus and of $M$. pyrifera gametophytes made it necessary to use small tufts of algal material, which are difficult to handle because of their size and shape and do not attach well to Poly L-lysine-coated slides. To reduce the risk of loosing the samples, tubes were used to incubate and wash them (see Suppl. Note S1).

$v B P O$ has previously been shown to play a role in the response of E. siliculosus Ec $32 \mathrm{~m}$ against pathogens ${ }^{35}$ and more generally, in the responses of kelps to elicitors ${ }^{40}$. RCA-FISH was tested without success on the algal material (data not shown), but smFISH allowed detection of $v B P O \mathrm{mRNAs}$ in Ec32m cells infected with the phytomyxid M. ectocarpii (Fig. 2f-h, Suppl. Fig. S11g-i). Likewise, signals were detected in M. ectocarpii infected M. pyrifera cells (Suppl. Fig. S11a-f). In both cases, signals were dot-like, yet much more confined than in the plant and phytomyxids tested.

\section{Discussion}

Here, we demonstrate the feasibility of localising mRNA transcripts of phytomyxid pathogens and their plant and algal hosts, which to our knowledge is the first time this method has been used on brown algae, phytomyxids and to analyse biological interactions between two eukaryote species and in environmental samples. Localising mRNAs permits the identification and analyses of spatiotemporal pattern of mRNAs in the cytoplasm. Both methods tested (smFISH, RCA-FISH) are readily accessible once a gene of interest in biological interactions is identified. Using mRNA FISH allows to overcome important technical bottlenecks that hamper research on important non-model pathogens, plants or algae $\mathrm{e}^{20}$. Our protocols therefore have huge potential to move our knowledge of these interactions beyond the limitations of RNAseq and organisms for which genetic amendments are possible ${ }^{5}$ since the genes of interest can be studied in the environment of the direct interaction. Using clubroots from commercial fields, we directly show the applicability of the methods to investigate host-pathogen interactions in wild type populations and plants grown under natural conditions. The here presented methods will greatly increase our understanding of subcellular gene expression pattern, similar to the leap in knowledge that happened in model organisms in the coming years ${ }^{41-44}$.

FISH is-as any nucleic acid based method-very adaptable to the needs of the user. A multitude of protocols are available, many of which are variations of the two protocols tested here reviewed by ${ }^{45}$. When selecting the most suitable method a couple of factors need to be kept in mind (Table 2). Generally, it can be said that the more complex a biological system, the less complex the method of choice should be: the efficacy for the detection of phytomyxid mRNAs was $15 \%$ higher when the less complex smFISH method was used than with RCA-FISH. However, smFISH requires mRNAs which are longer than $500 \mathrm{bp}$ to fit a relevant number of probes, while this size restriction does not apply to RCA-FISH. We proved here that the two contrastingly complex FISH methods can be used to generate meaningful results (Table 2).

The mRNA signal pattern differed between plants, brown algae and P. brassicae (Fig. 2). Plant mRNAs followed the pattern that were expected based on the pioneering works on smFISH in plants ${ }^{15}$ : mRNA signals were dot-like and distributed more or less evenly in cells and were similar in size and shape (Fig. 2i,j, Suppl. Fig. S10). The mRNA pattern in brown algae are comparable to the ones in plants, although signals were somewhat more restricted (Fig. 2f-h, Suppl. Fig. S11). The mRNA pattern observed in phytomyxids are only comparable when few mRNAs are detected in the plasmodia (e.g. Fig. 2b). However, when many mRNAs are present close to each other 


\begin{tabular}{|c|c|c|}
\hline & RCA FISH & smFISH \\
\hline Pros & $\begin{array}{l}\text { Signal amplification in theory allows to monitor single copy mRNAs also in samples } \\
\text { with a high fluorescent background } \\
\text { Specificity: Highly specific probes can be designed to distinguish between paralogues } \\
\text { or SNPs } \\
\text { No gene length limitation: short ( }<500 \mathrm{bp}) \text { genes can be analysed } \\
\text { Modular: Possibility of combination with in situ proximity ligation assays to collect } \\
\text { information on mRNA-protein interactions or post-translational modification (not } \\
\text { tested in the scope of this paper) }\end{array}$ & $\begin{array}{l}\text { Signal amplification in theory allows to monitor single copy mRNAs in samples with } \\
\text { a high fluorescent background } \\
\text { Complexity: easy probe design, few steps minimising contamination risks } \\
\text { Cell permeability: small probes, no large functional molecules involved } \\
\text { Cost of reagents: most reagents needed are standard lab consumables } \\
\text { Time: Fast protocol, ca. } 1 \text { day from sample to image, hands on time ca } 3 \mathrm{~h}\end{array}$ \\
\hline Cons & $\begin{array}{l}\text { Complexity: many steps increase the risk of RNase contamination or errors } \\
\text { Cell permeability: Involves multiple steps requiring large enzymes which need to } \\
\text { reach the cytoplasm. This is a major drawback for use in the plant/algal system } \\
\text { Costs of probes: The expensive LNA- and Padlock probes need to be designed for } \\
\text { each gene (ca. } 400 € \text { per gene for } ~ 200 \text { reactions) } \\
\text { Costs of reagents: pricey reagents and enzymes are used (ca } 75 € \text { per reaction) } \\
\text { Time: ca. } 2 \text { days from sample to image, of which there are ca } 6 \mathrm{~h} \text { hands on time }\end{array}$ & $\begin{array}{l}\text { Specificity: using standard FISH probes in a "string of beads" manner opens possibil- } \\
\text { ity of false positives for isoforms, orthologues or conserved gene families } \\
\text { Gene length limitation: Short mRNA sequences (<500 bp) are not suitable for } \\
\text { smFISH } \\
\text { Costs of probes: } 24-48 \text { labelled probes are needed for each gene. Some companies } \\
\text { offer discounts on smFISH probes (ca. } 500-800 € \text { depending on the number of probes } \\
\text { and the fluorophore, } \sim 1,000+\text { reactions) }\end{array}$ \\
\hline
\end{tabular}

Table 2. Advantages and disadvantages of RCA-FISH and smFISH. Prices can vary and are estimates based on Austrian prices 2019 including 20\% VAT.

the individual mRNAs do not resolve and are displayed as larger areas, especially in the maximum projections of the z-stacks (Fig. 2, Fig. 3, Video S1). Although phytomyxid plasmodia are similar in size and shape to their host cell (Fig. 3), each plasmodium has to be interpreted as an aggregation of hundreds to thousands small cells with an individual diameter of 3-5 $\mu \mathrm{m}$ and each with its own nucleus (compare e.g. Fig. 2b insert, or Fig. 2f-h). So the space which can be populated by mRNAs is much more confined than in the comparably gargantuan host cells. This is visually amplified in maximum projections of z-stacks, because one plasmodium contains more than one layer of cells (one layer per 3-5 $\mu \mathrm{m}$ ). It is, however, very important to note that these technical and biological limitations are clearly counterbalanced by the amount of biological information that can be gathered.

Here we show that both smFISH and RCA-FISH methods are suitable for in situ mRNA monitoring in the host and the pathogen providing good quality spatiotemporal information for otherwise unaccessible biotic interactions. While analysing three totally different biological systems (plants, algae, phytomyxids) it became clear that the overall success and efficiency of the method is determined by the fixation of the mRNAs in the sample material and the permeability of the cell walls, both limiting factors that differ across organisms. Fixation methods and the duration of storage post-fixation influenced the number of cells in which signals could be detected; however, this was different across sample types and genes so no clear maximum or minimum duration of storage could be established. Since decreasing signal intensities caused by RNA degradation during storage can be a limitation of the successful implementation of the method, we recommend using the samples as soon as possible after harvesting. However, we found that samples kept in an RNase-free environment give good results after more than one year. Another reason for decreasing signals can be formaldehyde mediated covalent interlinking of mRNAs and the RNA-binding proteins which are responsible for the transport of the RNA to the site of translation ${ }^{14,46}$, or mRNA secondary structures that do not permit the binding of the probes to the sites of interest ${ }^{47}$. Because of this, we recommend not to store the samples in the formaldehyde containing fixative, but to move them to pure ethanol for long term storage. RNA-binding proteins and mRNA secondary structure can impact on the success of the detection method without the fixation bias mentioned above, because both can limit the accessibility of the target site for probes ${ }^{46}$.

Also, the permeability of cell walls and plant tissue as a whole is a limitation for FISH-based methods. In this study, RCA-FISH was not adaptable to study interactions in filamentous algae, most likely because the enzymes needed could not permeate the cell walls. Cutting of the algae without destruction of the cell arrangement is very difficult and usually results in a loss of spatial information. All tested permeabilisation efforts did not improve the signal yield. Also in plants the efficacy of the mRNA detection was lower in RCA-FISH, as signals were only visible in cells which were cut open, but never in cells with an intact cell wall. The cooperatively small probes used for smFISH could be used on all samples without additional permeabilisation steps.

In this study, we determined the expression and localisation pattern of three pathogen genes, one plant and one brown algal gene. All mRNAs chosen had a putative function assigned to pre-existing information on the expected expression pattern. However, the single cell resolution of our experiments resulted in information, which is already improving our understanding of the biological interaction. These findings also showcase the potential gain of using mRNA FISH to advance our knowledge on plant pathogen interactions beyond the state of the art.

Biologically most interesting was the expression pattern of PbBSMT, a SABATH-type methyltransferase produced by $P$. brassicae. This methyltransferase has structural similarities to plant methyltransferases and is able to methylate SA, but with a much higher efficacy in suppressing SA levels and its associated effects through methylation, than the plant methyltransferase ${ }^{48}$. Previous qPCR analysis of its expression pattern showed, that its expression during clubroot development is highest when the concentration of SA in the roots peaks, which is the reason why a role in disease development of this gene has been discussed ${ }^{27,33}$. In our in situ experiments, PbBSMT mRNAs started to appear in small developing plasmodia (Suppl. Fig S6, S7). Small amounts of PbB$S M T$ have been detected previously during early infection in EST (expressed sequence tag) libraries ${ }^{49}$ and callus culture transcriptome analyses ${ }^{50}$. We observed mRNAs of PbBSMT in small plasmodia, which appear to move from cell to cell (Suppl. Fig. S7). There is anecdotal evidence that plasmodia can move from cell to cell using 
cell wall breaks or plasmodesmata ${ }^{51-53}$, but our results are the first to show that this movement is linked to the expression of a putative effector that alters the host defence response.

Using FISH we clearly demonstrate, that PbBSMT mRNAs start to increase when $P$. brassicae transitions from plasmodial growth to resting spore formation. The detected mRNAs peaked when young, immature resting spores became recognisable (Fig. 3). These results again confirm findings from previous studies ${ }^{27,33}$, but our results are the first to pinpoint these changes to specific life cycle stages. Notably PbBSMT mRNAs accumulate around the developing resting spores in the sporogenic plasmodia (Fig. 3, Suppl. Video 1). This accumulation of PbBSMT mRNAs around the developing resting spores is striking, because during spore formation chitin is produced ${ }^{24,54}$, which is one of the best studied elicitors of plant defence and induces (amongst others) SA production ${ }^{55}$. The results presented here therefore reinforce the previously established hypothesis that PbBSMT is produced to inactivate SA produced by the host in response to chitin ${ }^{24,33,48}$. However, methylsalicylate (MeSA) is a more volatile and membrane-permeable form of SA and is either excreted via the leaves or an inducer of systemic responses in plants ${ }^{56}$. MeSA was specifically emitted from Arabidopsis leaves infected with P. brassica $e^{33}$. Combined with findings from previous studies ${ }^{27,33,48}$, our observations strongly support the role in host defence suppression of PbBSMT, making it a very interesting target for future studies.

Therefore, we could confirm a direct interaction and interference of phytomyxids on the transcriptional status of infected cells using smFISH. Roots of brassicas infected with $P$. brassicae show a marked accumulation of starch ${ }^{39,57}$. MEX1, a gene coding for a maltose transporter essential for transporting maltose from the amyloplast to the cytosol ${ }^{38}$. With smFISH we could localise MEX1 mRNAs in plant cells containing amyloplasts and plasmodia of P. brassicae (Suppl. Fig. S10). The presence of mRNAs is an indicator of ongoing synthesis of a host protein, because of the short half live of mRNAs in vivo ${ }^{58}$. Therefore, it is likely that the MEX1 protein is activated by growing $P$. brassicae plasmodia to mediate energy supply from the host to the pathogen.

The brown algal $v B P O$ has previously been linked to stress response ${ }^{34,35}$. Here we could confirm that $v B P O$ mRNAs are located in E. siliculosus and M. pyrifera cells, which show early infections with M. ectocarpii, while in cells where the infection has advanced to sporangial development no signals were identified. This confirms that brown algae, like plants, show a localised stress response to plasmodiophorid pathogens. Whether or not this type of stress response is a general pattern in brown algae or if this is specific for infections with phytomyxids was beyond the scope of this study.

We could clearly show that single molecule FISH methods are suitable to study the activity of mRNAs in complex pathogen-host interactions. Overall smFISH proved to be the faster approach while at the same time leading to more reliable results. RCA FISH on the other hand will allow to study smaller mRNAs, so despite its more complex nature and increased handling complexity it needs to be considered for applications for which smFISH is not suitable. A wider application of these methods in the future will result in standardisation of the sample preparation, imaging and data analyses. Overall FISH based mRNA visualisation methods can and should be seen as a valuable tool for our understanding of biotrophic interactions at the single cell level and to learn more about the behavior of the different stages of the phytomyxid life cycle in a biological context.

Received: 29 November 2019; Accepted: 5 August 2020

Published online: 31 August 2020

\section{References}

1. Libault, M., Pingault, L., Zogli, P. \& Schiefelbein, J. Plant systems biology at the single-cell level. Trends Plant Sci. 22, 949-960. https://doi.org/10.1016/j.tplants.2017.08.006 (2017).

2. Moor, A. E. \& Itzkovitz, S. Spatial transcriptomics: Paving the way for tissue-level systems biology. Curr. Opin. Biotechnol. 46, 126-133. https://doi.org/10.1016/j.copbio.2017.02.004 (2017).

3. Zeilinger, S. et al. Friends or foes? Emerging insights from fungal interactions with plants. FEMS Microbiol. Rev. 40, 182-207. https ://doi.org/10.1093/femsre/fuv045 (2016).

4. Kemen, E. \& Jones, J. D. G. Obligate biotroph parasitism: Can we link genomes to lifestyles?. Trends Plant Sci. 17, 448-457. https ://doi.org/10.1016/j.tplants.2012.04.005 (2012).

5. Buxbaum, A. R., Haimovich, G. \& Singer, R. H. In the right place at the right time: Visualizing and understanding mRNA localization. Nat. Rev. Mol. Cell Biol. 16, 95-109. https://doi.org/10.1038/nrm3918 (2015).

6. Schuller, A., Kehr, J. \& Ludwig-Muller, J. Laser microdissection coupled to transcriptional profiling of Arabidopsis roots inoculated by Plasmodiophora brassicae indicates a role for brassinosteroids in clubroot formation. Plant Cell Physiol. 55, 392-411. https:// doi.org/10.1093/pcp/pct174 (2014).

7. Müller, D. B., Vogel, C., Bai, Y. \& Vorholt, J. A. The plant microbiota: Systems-level insights and perspectives. Annu. Rev. Genet. 50, 211-234. https://doi.org/10.1146/annurev-genet-120215-034952 (2016).

8. Vandenkoornhuyse, P., Quaiser, A., Duhamel, M., Le Van, A. \& Dufresne, A. The importance of the microbiome of the plant holobiont. New Phytol. 206, 1196-1206. https://doi.org/10.1111/nph.13312 (2015).

9. Egan, S. et al. The seaweed holobiont: Understanding seaweed-bacteria interactions. FEMS Microbiol. Rev. 37, 462-476. https:// doi.org/10.1111/1574-6976.12011 (2013).

10. Misra, B. B., Assmann, S. M. \& Chen, S. X. Plant single-cell and single-cell-type metabolomics. Trends Plant Sci. 19, 637-646. https ://doi.org/10.1016/j.tplants.2014.05.005 (2014).

11. Wang, D. J. \& Bodovitz, S. Single cell analysis: The new frontier in “omics". Trends Biotechnol. 28, 281-290. https://doi.org/10.1016/j. tibtech.2010.03.002 (2010)

12. Weibrecht, I. et al. In situ detection of individual mRNA molecules and protein complexes or post-translational modifications using padlock probes combined with the in situ proximity ligation assay. Nat. Protoc. 8, 355-372. https://doi.org/10.1038/nprot .2013 .006 (2013).

13. Trcek, T., Lionnet, T., Shroff, H. \& Lehmann, R. mRNA quantification using single-molecule FISH in Drosophila embryos. Nat. Protoc. 12, 1326-1348. https://doi.org/10.1038/nprot.2017.030 (2017).

14. Niessing, D., Jansen, R. P., Pohlmann, T. \& Feldbrugge, M. mRNA transport in fungal top models. Wiley Interdiscip. Rev.-RNA https://doi.org/10.1002/wrna.1453 (2018). 
15. Duncan, S., Olsson, T. S. G., Hartley, M., Dean, C. \& Rosa, S. A method for detecting single mRNA molecules in Arabidopsis thaliana. Plant Methods https://doi.org/10.1186/s13007-016-0114-x (2016).

16. Francoz, E. et al. Complementarity of medium-throughput in situ RNA hybridization and tissue-specific transcriptomics: Case study of Arabidopsis seed development kinetics. Sci. Rep. https://doi.org/10.1038/srep24644 (2016).

17. Bruno, L. et al. Multi-probe in situ hybridization to whole mount Arabidopsis seedlings. Int. J. Dev. Biol. 55, 197-203. https://doi. org/10.1387/ijdb.103132lb (2011).

18. Chen, K. H., Boettiger, A. N., Moffitt, J. R., Wang, S. Y. \& Zhuang, X. W. Spatially resolved, highly multiplexed RNA profiling in single cells. Science https://doi.org/10.1126/science.aaa6090 (2015).

19. Baroja-Fernandez, E. et al. Sucrose synthase activity in the sus1/sus2/sus3/sus4 Arabidopsis mutant is sufficient to support normal cellulose and starch production. Proc. Natl. Acad. Sci. USA 109, 321-326. https://doi.org/10.1073/pnas.1117099109 (2012).

20. Schwelm, A. et al. Not in your usual Top 10: Protists that infect plants and algae. Mol. Plant Pathol. 19, 1029-1044. https://doi. org/10.1111/mpp.12580 (2018).

21. Murúa, P. et al. Maullinia braseltonii sp nov (Rhizaria, Phytomyxea, Phagomyxida): A cyst-forming parasite of the bull kelp Durvillaea spp. (Stramenopila, Phaeophyceae, Fucales). Protist 168, 468-480. https://doi.org/10.1016/j.protis.2017.07.001 (2017).

22. Neuhauser, S., Huber, L. \& Kirchmair, M. Is Roesleria subterranea a primary pathogen or a minor parasite of grapevines? Risk assessment and a diagnostic decision scheme. Eur. J. Plant Pathol. 130, 503-510. https://doi.org/10.1007/s10658-011-9769-3 (2011).

23. Maier, I., Parodi, E., Westermeier, R. \& Muller, D. G. Maullinia ectocarpii gen. et sp. nov. (Plasmodiophorea), an intracellular parasite in Ectocarpus siliculosus (Ectocarpales, Phaeophyceae) and other filamentous brown algae. Protist 151, 225-238. https:// doi.org/10.1078/1434-4610-00021 (2000).

24. Schwelm, A. et al. The Plasmodiophora brassicae genome reveals insights in its life cycle and ancestry of chitin synthases. Sci. Rep. 5,11153 (2015).

25. Rolfe, S. A. et al. The compact genome of the plant pathogen Plasmodiophora brassicae is adapted to intracellular interactions with host Brassica spp. BMC Genomics 17, 272 (2016).

26. Irani, S. et al. Transcriptome analysis of response to Plasmodiophora brassicae infection in the Arabidopsis shoot and root. BMC Genomics 19, 23 (2018).

27. Bulman, S. et al. Arabidopsis thaliana expressing PbBSMT, a gene encoding a SABATH-type methyltransferase from the plant pathogenic protist Plasmodiophora brassicae, show leaf chlorosis and altered host susceptibility. Plant Biol. (Stuttg) 21(Suppl 1), 120-130. https://doi.org/10.1111/plb.12728 (2019).

28. Singh, K., Tzelepis, G., Zouhar, M., Ryšánek, P. \& Dixelius, C. The immunophilin repertoire of Plasmodiophora brassicae and functional analysis of PbCYP3 cyclophilin. Mol. Genet. Genomics 293, 381-390. https://doi.org/10.1007/s00438-017-1395-0 (2018).

29. Cormier, A. et al. Re-annotation, improved large-scale assembly and establishment of a catalogue of noncoding loci for the genome of the model brown alga Ectocarpus. New Phytol. 214, 219-232. https://doi.org/10.1111/nph.14321 (2016).

30. Ye, N. et al. Saccharina genomes provide novel insight into kelp biology. Nat. Commun. 6, 6986. https://doi.org/10.1038/ncomm s7986 (2015)

31. Farnham, G., Strittmatter, M., Coelho, S., Cock, J. M. \& Brownlee, C. Gene silencing in Fucus embryos: Developmental consequences of RNAi-mediated cytoskeletal disruption. J. Phycol. 49, 819-829. https://doi.org/10.1111/jpy.12096 (2013).

32. Archibald, J. M. \& Keeling, P. J. Actin and ubiquitin protein sequences support a cercozoan/foraminiferan ancestry for the plasmodiophorid plant pathogens. J. Eukaryot. Microbiol. 51, 113-118. https://doi.org/10.1111/j.1550-7408.2004.tb00172.x (2004).

33. Ludwig-Müller, J. et al. A novel methyltransferase from the intracellular pathogen Plasmodiophora brassicae methylates salicylic acid. Mol. Plant Pathol. 16, 349-364 (2015).

34. Leblanc, C. et al. Vanadium haloperoxidases: From the discovery 30 years ago to X-ray crystallographic and V K-edge absorption spectroscopic studies. Coord. Chem. Rev. 301, 134-146. https://doi.org/10.1016/j.ccr.2015.02.013 (2015).

35. Strittmatter, M. et al. Infection of the brown alga Ectocarpus siliculosus by the oomycete Eurychasma dicksonii induces oxidative stress and halogen metabolism. Plant Cell Environ. 39, 259-271. https://doi.org/10.1111/pce.12533 (2016).

36. West, J. A. \& McBride, D. L. Long-term and diurnal carpospore discharge patterns in the Ceramiaceae, Rhodomelaceae and Delesseriaceae (Rhodophyta). Hydrobiologia 398, 101-114. https://doi.org/10.1023/a:1017025815001 (1999).

37. Schneider, C. A., Rasband, W. S. \& Eliceiri, K. W. NIH Image to ImageJ: 25 years of image analysis. Nat. Methods 9, 671. https:// doi.org/10.1038/nmeth.2089 (2012).

38. Stettler, M. et al. Blocking the metabolism of starch breakdown products in Arabidopsis leaves triggers chloroplast degradation. Mol. Plant 2, 1233-1246. https://doi.org/10.1093/mp/ssp093 (2009).

39. Schuller, A. \& Ludwig-Müller, J. Histological methods to detect the clubroot pathogen Plasmodiophora brassicae during its complex life cycle. Plant. Pathol. 65, 1223-1237 (2016).

40. Cosse, A., Potin, P. \& Leblanc, C. Patterns of gene expression induced by oligoguluronates reveal conserved and environmentspecific molecular defense responses in the brown alga Laminaria digitata. New Phytol. 182, 239-250. https://doi.org/10.111 1/j.1469-8137.2008.02745.x (2009).

41. Robin, A. H. K., Hossain, M. R., Kim, H.-T., Nou, I.-S. \& Park, J.-I. Role of cytokinins in clubroot disease development. Plant Breed. Biotechnol. 7, 73-82 (2019).

42. Gaspar, I. \& Ephrussi, A. Strength in numbers: Quantitative single-molecule RNA detection assays. Wiley Interdiscip. Rev. Dev. Biol. 4, 135-150. https://doi.org/10.1002/wdev.170 (2015).

43. Lee, C., Roberts, S. E. \& Gladfelter, A. S. Quantitative spatial analysis of transcripts in multinucleate cells using single-molecule FISH. Methods 98, 124-133 (2016).

44. Medioni, C. \& Besse, F. The secret life of RNA: Lessons from emerging methodologies. In RNA Detection: Methods and Protocols (ed. Gaspar, I.) 1-28 (Springer, New York, 2018).

45. van Gijtenbeek, L. A. \& Kok, J. Illuminating messengers: An update and outlook on RNA visualization in bacteria. Front. Microbiol. 8, 1-19. https://doi.org/10.3389/fmicb.2017.01161 (2017).

46. Foley, S. W., Kramer, M. C. \& Gregory, B. D. RNA structure, binding, and coordination in Arabidopsis. Wiley Interdiscip. Rev. RNA 8, e1426. https://doi.org/10.1002/wrna.1426 (2017)

47. Ding, Y. et al. In vivo genome-wide profiling of RNA secondary structure reveals novel regulatory features. Nature 505, 696. https ://doi.org/10.1038/nature12756 (2013).

48. Djavaheri, M. et al. Mimicking the host regulation of salicylic acid: A virulence strategy by the clubroot pathogen Plasmodiophora brassicae. Mol. Plant Microbe Interact. 32, 296-305. https://doi.org/10.1094/mpmi-07-18-0192-r (2019).

49. Bulman, S., Siemens, J., Ridgway, H. J., Eady, C. \& Conner, A. J. Identification of genes from the obligate intracellular plant pathogen, Plasmodiophora brassicae. FEMS Microbiol. Lett. 264, 198-204 (2006).

50. Bulman, S. et al. Genomics of biotrophic, plant-infecting plasmodiophorids using in vitro dual cultures. Protist 162, 449-461. https://doi.org/10.1016/j.protis.2010.09.004 (2011).

51. Donald, E. C., Jaudzems, G. \& Porter, I. J. Pathology of cortical invasion by Plasmodiophora brassicae in clubroot resistant and susceptible Brassica oleracea hosts. Plant. Pathol. 57, 201-209. https://doi.org/10.1111/j.1365-3059.2007.01765.x (2008).

52. Mühlenberg, I., Schuller, A., Siemens, J., Kobelt, P. \& Ludwig-Müller, J. Plasmodiophora brassicae, the causal agent of clubroot disease, may penetrate plant cell walls via cellulase. Plant Prot. Sci. Prague 38, 69-72 (2003).

53. Riascos, D., Ortiz, E., Quintero, D., Montoya, L. \& Hoyos-Carvajal, L. Histopathological and morphological alterations caused by plasmodiophora brassicae in Brassica oleracea. Agron. Colomb. 29, 57-67 (2011). 
54. Cavalier-Smith, T. \& Chao, E. E. Y. Phylogeny of choanozoa, apusozoa, and other protozoa and early eukaryote megaevolution. J. Mol. Evol. 56, 540-563. https://doi.org/10.1007/s00239-002-2424-z (2003).

55. Fesel, P. H. \& Zuccaro, A. beta-glucan: Crucial component of the fungal cell wall and elusive MAMP in plants. Fungal Genet. Biol. 90, 53-60. https://doi.org/10.1016/j.fgb.2015.12.004 (2016).

56. Vlot, A. C., Pabst, E. \& Riedlmeier, M. Systemic signalling in plant defence. eLS https://doi.org/10.1002/9780470015902.a0001322. pub3 (2017).

57. Ludwig-Müller, J., Prinsen, E., Rolfe, S. A. \& Scholes, J. D. Metabolism and plant hormone action during clubroot disease. J. Plant Growth Regul. 28, 229-244 (2009).

58. Merchante, C., Stepanova, A. N. \& Alonso, J. M. Translation regulation in plants: An interesting past, an exciting present and a promising future. Plant J. 90, 628-653. https://doi.org/10.1111/tpj.13520 (2017).

\section{Acknowledgements}

JB and SN were funded by the Austrian Science Fund (FWF): Grant Y801-B16 (START-grant). CG has received funding from the European Union's Horizon 2020 research and innovation programme under the Marie Sklodowska-Curie Grant Agreement No 642575, and from the UK NERC under the grant agreement GlobalSeaweed (NE/L013223/1). We thank Stefan Ciaghi for providing the transcriptomic data for $M E X 1$. The authors want to thank Martin Kirchmair, Arne Schwelm, Mohammad Etemadi and Stefan Ciaghi for useful discussions.

\section{Author contributions}

J.B. and S.N. designed the research, collected, analysed and interpreted data and wrote the manuscript with feedback from all co-authors; J.B. performed the research; C.G. provided algal material and algal data; J.L.M. provided the P. brassicae strain e 3 and plant material. A.M.S. analysed the images. All authors read and contributed to the final MS.

\section{Competing interests}

The authors declare no competing interests.

\section{Additional information \\ Supplementary information is available for this paper at https://doi.org/10.1038/s41598-020-70884-4.}

Correspondence and requests for materials should be addressed to S.N.

Reprints and permissions information is available at www.nature.com/reprints.

Publisher's note Springer Nature remains neutral with regard to jurisdictional claims in published maps and institutional affiliations.

(c) (i) Open Access This article is licensed under a Creative Commons Attribution 4.0 International License, which permits use, sharing, adaptation, distribution and reproduction in any medium or format, as long as you give appropriate credit to the original author(s) and the source, provide a link to the Creative Commons license, and indicate if changes were made. The images or other third party material in this article are included in the article's Creative Commons license, unless indicated otherwise in a credit line to the material. If material is not included in the article's Creative Commons license and your intended use is not permitted by statutory regulation or exceeds the permitted use, you will need to obtain permission directly from the copyright holder. To view a copy of this license, visit http://creativecommons.org/licenses/by/4.0/.

(C) The Author(s) 2020 